\title{
Torque Ripple Minimization in Switched Reluctance Motor using ANFIS Controller
}

\author{
V. PUSHPARAJESH ${ }^{1}$, NANDISH B M ${ }^{2}$, MARULASIDDAPPA H B 3 \\ ${ }^{1}$ Department of Electrical and Electronic Engineering, Jain University, Bangalore, Karnataka, INDIA \\ ${ }^{2,3}$ Department of Electrical Engineering, JIT, VTU, Davanagere, Karnataka, INDIA
}

\begin{abstract}
An inborn torque swell portrays changed hesitance innovation from traditional innovation. A definitive target of this paper is to minimize the torque wave of the exchanged hesitance engine drive utilizing Artificial Network Fuzzy Inference System based direct torque conspire. In the proposed controller arrange proper bits of information are picked for preparing and testing. The best possible choice of the learning rate and energy will help in weight change. The Intelligent controller gives high power over motor torque and speed, lessens rise time just as overshoot. Here the blunder is decreased which demonstrates that the determination of voltage vectors from the vector table is exact and its outcomes in better torque reaction over a wide scope of speed. The reenactment results uncover that the torque swells fluctuate between $3.75 \%$ to $2.25 \%$ for the variety in load torque and the drive speed. The experimental results for the proposed controller reveal that the torque ripple varies between $3.9 \%$ to $2.4 \%$ for the variation in speed. Both the recreation and equipment results delineate the effectiveness of the controller.
\end{abstract}

Key-Words: - Switched Reluctance motor, Torque ripple, Direct torque control

Received: October 10, 2020. Revised: February 27, 2021. Accepted: March 20, 2021. Published: March 31, 2021.

\section{Introduction}

In the present scenario, the combination of robust and adaptive along with intelligent control appears to be the most important research accomplishment in the drive control area. The torque ripple along with the speed control of switched reluctance motor drive is carried out by introducing fuzzy based Intelligent controller [1]. The sensorless speed of the switched reluctance motor is achieved accurately using stator flux estimation technique [2]. The least torque swell rate can be accomplished by differing the stator and rotor post grasp which in turn reduce the torque ripple in switched reluctance motor [3]. Speed control along with motor parameter operating point and noise is performed using an intelligent controller based on brain emotional learning [4]. The torque ripple in four phase switched reluctance motor can be minimized using Neural Network over a wide speed range [5]. Torque ripple in the stwitched reluctance motor can be improved by using the destructive interferences technique [6]. The switched reluctance motor speed with parameter variation and external load disturbances can be achieved by using robust adaptive neural network controller [7]. A hybrid controller based PI tuning technique to control the speed of switched reluctance motor which is highly non-linear in nature [8]. Hybrid Intelligent controller is deputed to reduce the torque ripple over the wide speed range [9]. A control technique is adopted to control the speed of SRM by continuous conduction mode using four parameters [10]. The time response of the incoming and the outgoing phases of instantaneous torque is different and the torque ripple in the reluctance drive can be minimized by the overlap angle during the commutation period [11]. The high-performance speed control of switched reluctance motor drive is possible by implementing the current sharing method [12]. The Speed of the Switched reluctance motor as well as torque ripple can also be controlled using non-dominated genetic algorithm [13]. A comparative study between the Intelligent controller and classical PI controller for speed control of SRM has been carried out to shown the speed response in terms of settling time [14]. The maximum torque value at a minimum mass can be achieved by using the combination of FEM and seeker optimization algorithm [15]. The speed control mechanism along with torque ripple to obtain a better settling time in torque, speed and current is determined by MOL algorithm [16]. The torque ripple in switched reluctance motor drive can be minimized by using a novel phase current profiling method [17]. The 
switched reluctance motor speed control along with the torque ripple minimization is achieved using by considering the magnetic saturation effect [18]. The Self tuning TSK-Fuzzy control strategy is used to control the speed of the switched reluctance motor drive over a wide range [19]. The high-performance speed control of switched reluctance motor drive is possible by implementing the current sharing method [20]. Artificial Intelligent controller is used to control the speed of the reluctance drive [21]. In this paper the proposed controller is implemented by the integration of a neural network with the direct torque control (DTC) and optimized by using Fuzzy controller for SRM drive.

\section{ANFIS on the Torque Ripple Reduction}

ANFIS is a wise controller that is shaped by the blend of neural system and fluffy rationale framework [22]. The hybridization of the two ideals yields the talents of learning, boundless change and consolidating prior statistics. ANN can also be making use of to get familiar with the involvement honours for fleecy outlines, to shape IF-THEN principles, or to improve choice reasoning [23]. The sincere idea of the two superlative models is a cross breed neural/feathery outline, which gets the advantages of both the systems. This thought is used in working up the ANFIS regulator in this area. A neuro-cushioned structure has a neural-compose configuration worked from soft reasoning. Sorted out data is arranged as feathery rules, while modifying and learning capacities of neural frameworks are held. Ace data can accelerate and estimation accuracy.

The blended method of the learning intensity of the NNs with the information portrayal of FL has made another half and half procedure, called neuro-fluffy networks. ANFIS comprises of five layers. The principal layer comprises of participation capacities as calculation layers. The enrolment can be any kind of participation work. The subsequent layer is utilized to discover least or result of contributions from rule base. The third layer is utilized to standardize the loads for the system. The fourth layer yield is the direct capacity of third layers yield and produces the standard yield. In the fifth layer, each standard yield is summarized. This strategy gives a genuinely decent choice of exchanging voltage vectors which bring about appropriate exchanging of the inverter switches. The choice of appropriate obligation proportion bringing about legitimate turn on and turn off of the force electronic gadgets brings about the correct excitation of the SRM drive. A superior excitation of the stator posts brings about the decrease of torque waves, vibration and sea-going commotion in the SRM drive which improves the productivity of the drive and makes it reasonable for a large portion of the applications.

\section{Modelling of ANFIS Controller}

The versatile system based fluffy induction framework is an information driven strategy speaking to a neural system approach for the arrangement of capacity guess issues. Information driven systems for the union of ANFIS systems are regularly founded on bunching a preparation set of numerical examples of the obscure capacity to be approximated.

The activity of the various layers is spoken to as a calculation as talked about underneath. But the neural system obstruct the structure contains indistinguishable segments from fis. The system structure is shaped with a lot of 5 interconnected system layers, viz., 11 to 15 .

In ANFIS controller sugeno type neuro fluffy is utilized with torque as info variable to controller. The yield alluded from the controller is the current which is taken care of to the contribution of the force converter. The assortments of information are acquired by shifting the boundaries in reproduction. Info and target are gathered.

The ANFIS neuro-fuzzy system operation can be summarized in two steps:

1. The set of membership functions has to be chosen, their number and corresponding shape.

2. The input-output training data are used by the clustering study of the data to identify natural groups of data, to obtain a concise and significant representation of the system.

Before going for the controller stoop utilizing the ANFIS conspire, it is important to go for a numerical model of the exchanged hesitance engine alongside the controller scientific model, which can be additionally utilized for reenactment purposes. The non-direct numerical model of the drive is talked about in Chapter 1 which is utilized 
here in the Simulink model. The essential structure of the ANFIS coordination controller created in this examination limits the torque wave of the SRM drive by methods for legitimate determination of the voltage vectors from the vector table.

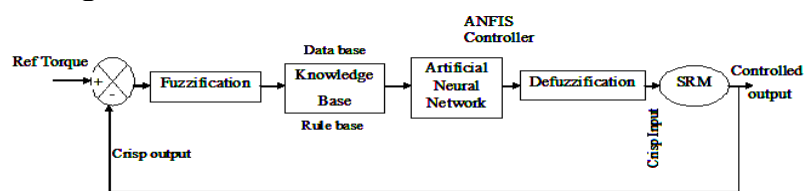

Figure 1 Block diagram of ANFIS Controller

The block diagram of the proposed system is shown in Figure. 1. Inputs to the ANFIS controller, the error and the change in error, are modeled using Equations (1) and (2) as follows:

$$
\begin{gathered}
e(k)=T_{r e f}-T_{r} \\
\Delta e(k)=e(k)-e(k-1)
\end{gathered}
$$

where Tref is the torque reference, $\operatorname{Tr}$ is the real engine torque, $\mathrm{e}(\mathrm{k})$ is the blunder and $\Delta \mathrm{e}(\mathrm{k})$ is the adjustment in mistake. The fresh information are changed over into semantic factors by the fuzzification unit which is then given as contribution to the standard base square.

The information sources are given to the ANFIS controller in the wake of being fuzzified utilizing the fluffy sets. The preparation of neural system is made so as to choose the correct arrangement of rule base. When the best possible principles are chosen and terminated, the control signal required to get the ideal yields is created. The sources of info are fuzzified utilizing the fluffy sets and are given as contribution to the ANFIS controller. The standard base clarified in Chapter 2 is likewise utilized in this part for a similar dynamic purposes to plan the ANFIS controller. The structure of the ANFIS controller is appeared in Figure 2.

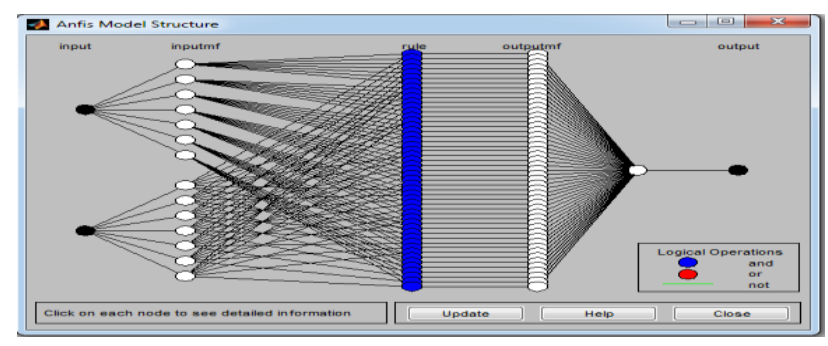

Figure 2 ANFIS Structure

A lot of 49 fluffy standards is composed dependent on the pervious information or articulations. The standard based square is then connected to the neural system hinder .The back proliferation calculation is utilized for preparing the neural system so as to pick the best possible arrangement of rule base. The control sign to acquire the ideal yield is produced once the correct fluffy standards are chosen and terminated. Further, it needs to change over into numerical yield. The yield y is characterized by the Equation (3).

$$
y=\frac{\sum_{i=1}^{R} \mu^{i} a_{1}^{i} x_{1}+\wedge+\sum_{i=1}^{R} \mu^{i} a_{q}^{i} x_{q}}{\sum_{i=1}^{R} \mu^{i}}
$$

This controlled output y of the SRM drive is the weighted average of the proper rule-based outputs that are determined by the back-propagation algorithm.

\section{ANFIS Based Direct Torque Control}

Because of intrinsic nonlinear attractive and saliency post nature the torque created in SRM is very much described by incredible motions, even if there should arise an occurrence of consistent stage excitation current. The Block diagram of the proposed control system is shown in figure 3. The main contrast is that the hysteresis torque controller is supplanted by the ANFIS controller. In this strategy, the torque swell is limited by choosing the appropriate exchanging vectors utilizing neurofluffy pay method. The contributions to the ANFIS compensator are the blunder torque taken from comparator which thinks about the genuine torque and the reference torque acquired from the ordinary PI controller. The status signal alongside the motion signal is utilized to choose the voltage vectors dependent on which the customary hilter kilter converters are worked. The neuro-fluffy compensator is with torque input including seven phonetic standards with triangular structure participation capacities. The information for preparing in neuro-fluffy compensator is gathered from reenactments of SRM control and yield from the compensator is fluctuated regarding change in the speed of SRM.

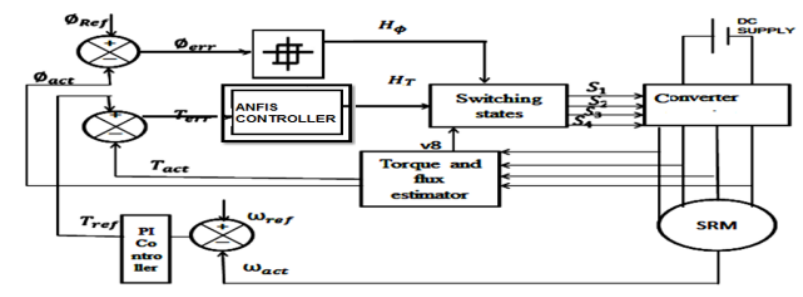




\section{Figure 3 Block Diagram of the Proposed Control System}

The standard consequents are balanced by a half and half controller calculation comprising of the mix of least square minimization and back engendering which is the preparation technique followed here. The DC segment at each learning cycle is evacuated so as to keep away from the wave compensator changing the yield mean estimation of the torque. The mistake limited yield from the traditional PI controller which is refereed as reference torque is contrasted and the genuine engine torque. The torque from the comparator is taken care of as the contribution to the ANFIS compensator whose yield target is a mistake free torque signal. The preparation information are gotten from reproductions of consistent state recreation activity of the exchanged hesitance drive framework. This informational collection is passed to the preparation calculation, so the torque blunder is deciphered by the repaid mistake data for every current edge pair. This preparation information which are the torque swell are organized against the reference torque and the rakish situation of the rotor.

The created ANFIS model structure has input neurons and yield neuron alongside shrouded layers (input enrollment work, rule base, participation work and accumulated yield). The preparation of the ANN by utilizing the fluffy guideline base for the choice of the correct and ideal standard is dealt with by the planned ANFIS controller. Note that 7 by 7 principles are utilized in the concealed layers. Both neuron 1 and neuron 2 are associated with 7 fluffy guidelines. The concealed layers contain 49-49 neurons to manage the issue (for determination of the correct standard base, in light of the fact that the standard base is composed haphazardly in fluffy, the neural system chooses the privilege ideal principle base to fire). The de-fuzzified yield is additionally used to create the exchanging beat to be applied to the IGBT inverter connect, which is utilized to lessen the torque swell in the SRM drive. The preparation calculation forms the preparation information to acquire the torque swell which is deciphered as mistake data for each pair.

The torque swell mistake is additionally diminished by straightening out the yield of the neuro fuzzy compensator and the procedure is proceeded until the base the torque swell breaking point is accomplished. The information are stacked from the workspace and it ought to converge with the testing information. The testing calculation checks the information which coordinate with preparing information and afterward testing and preparing information create fluffy derivation framework. It creates participation work for FIS. Create an underlying FIS model from the produce FIS part and afterward pick the quantity of preparing ages and preparing mistake resistance. In the proposed control plot the quantity of emphasis is seen as 100 and the quantity of straight and non direct boundaries is 147 and 42 .

\section{ANFIS Controller Based DTC Simulation Results}

This section presents the recreation aftereffects of the SRM drive dependent on direct torque control procedure with ANFIS controller. The simulink model of the SRM drive dependent on the DTC was created in MATLAB which involves Torque and Flux controller, Switching table, Power Converter, Physical model of SRM drive (8/6) and $\alpha-\beta$ change square. The reenactment was led to test the viability of the ANFIS Controller alongside DTC strategy at various velocities and at various burden conditions. The test is led with the SRM drive having the force yield of $1.5 \mathrm{~kW}$, evaluated $\mathrm{RPM}$ as $3800 \mathrm{rpm}$, appraised torque as $4 \mathrm{Nm}$ and the drive is applied a dc voltage of $\pm 120 \mathrm{~V}$. The adjusted Inductance and the unaligned Inductance are set as $10 \mathrm{mH}$ and $49 \mathrm{mH}$.

Different outcomes communicating the presentation utilizing the ANFIS controller for DTC based SRM drives are shown and the exhibitions are watched for the torque and the speed reference regarding static and dynamic conditions are delineated in the accompanying figures.

\subsection{Performance at rated load Condition}

The drive under the appraised load condition is animated with $100 \%$ of the evaluated speed. The relating torque and current reaction are appeared in Figure 4 For clearness over the reactions, the time scale variety for motion linkages, 4 stage flows and complete torque is taken as $0.71-$ 0.76 second. From the bend it is seen that a greatest current of $8 \mathrm{~A}$ is reached during the evaluated condition. 


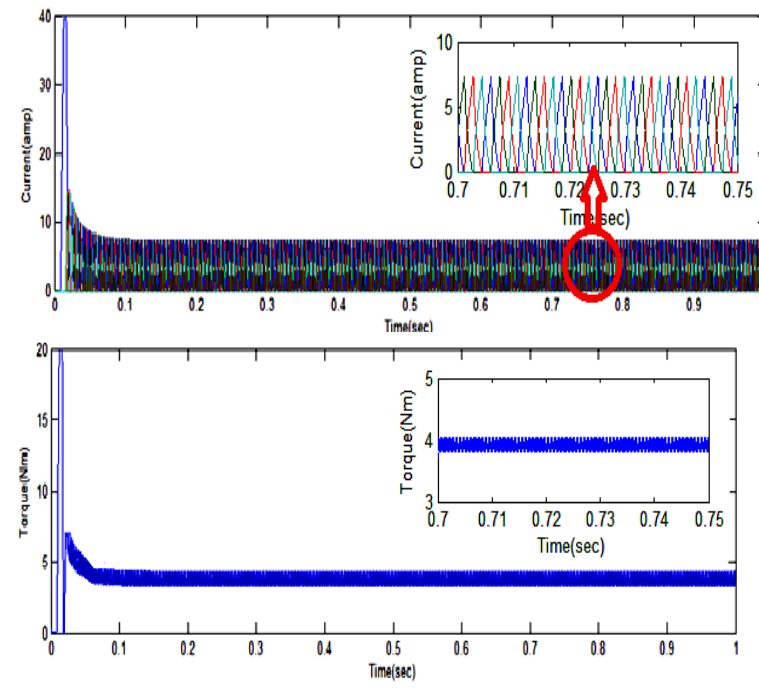

Figure 4 Current and Torque response ate rated load condition

The torque blunder is limited by the proposed controller which thusly chooses the correct exchanging vector that outcomes in decrease of torque swell as appeared in the above figure. The figure is additionally amplified to determine the variety of the torque swell precisely and its variety with various speed is appeared in Figure 5.

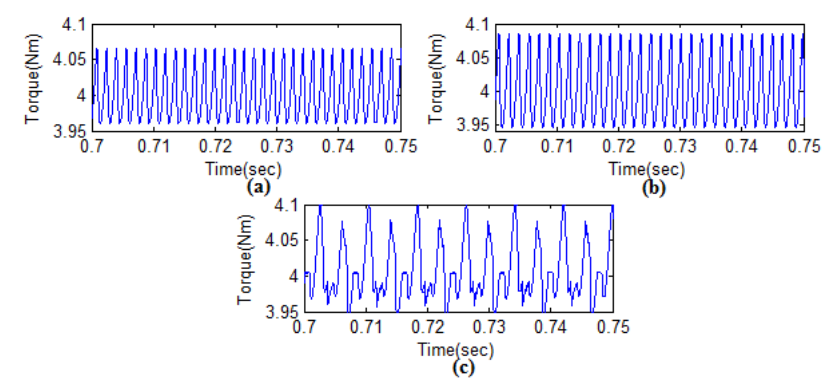

Figure 5 Torque ripples at rated torque

(a) Rated speed (b) half rated speed (c) $10 \%$ of
rated speed

The reaction bend (c) means that the torque yield (Tout) arrives at the evaluated torque in $0.04 \mathrm{~s}$ and from that point forward, the yield torque shifts between a most extreme torque (Tmax) of 4.1 $\mathrm{Nm}$ and a base torque (Tmin) of $3.95 \mathrm{Nm}$. The normal torque yield (Tavg) has been seen as 4.0 $\mathrm{Nm}$. The torque yield regarding swell is determined in rate as $3.75 \%$.

\subsection{Performance at $75 \%$ of the rated Load Torque}

The SRM drive is at first invigorated with $75 \%$ burden torque and with various evaluated speed condition. The relating torque and current reaction are appeared in Figure 6. From the bend it is seen that greatest current of $8 \mathrm{~A}$ is reached during the appraised condition.
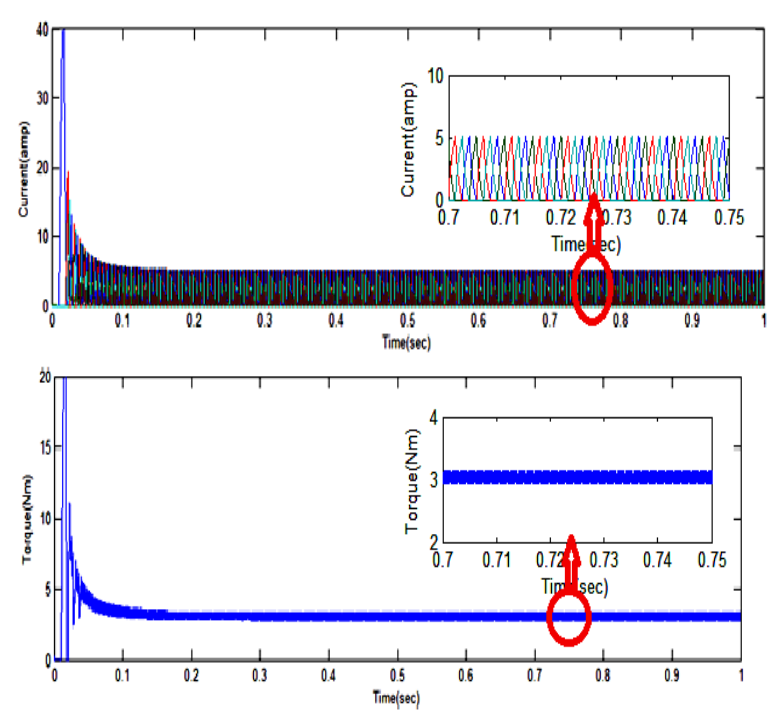

Figure 6 Phase Current and torque response at $75 \%$ of the rated load with rated speed

The torque reaction bend is expanded to show the exact variety of torque under determined torque condition as for wide scope of speed. The variety is watched and appeared in Figure 7.

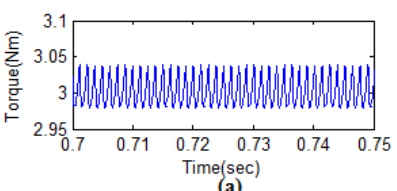

Time(sec)
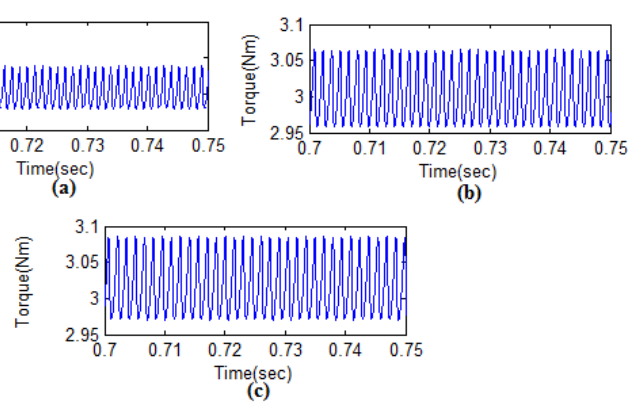

Figure 7 Torque responses at $75 \%$ of the rated load torque

(a) Rated speed (b) half rated speed (c) $10 \%$ of rated speed 
Torque bend (a) appear above uncovers that the torque yield (Tout) arrives at the $75 \%$ evaluated torque in $0.04 \mathrm{~s}$ and from that point forward, the yield torque shifts between a most extreme torque (Tmax) of $3.04 \mathrm{Nm}$ and a base torque (Tmin) of $2.98 \mathrm{Nm}$. The normal torque yield (Tavg) has been seen with a variation of $3.01 \mathrm{Nm}$ to $3.02 \mathrm{Nm}$. The torque swell yield is determined in rate as $2 \%$. To $3.6 \%$

\subsection{Performance at $50 \%$ of the rated Load Torque}

The SRM drive is at first simulated with half burden torque and at various appraised speed. The drive is reproduced with half of the evaluated load condition keeping the speed at the appraised condition. The comparing torque and current reaction are appeared in Figure 8. From the bend, it is seen that most extreme current of $3 \mathrm{~A}$ is reached during the evaluated condition.
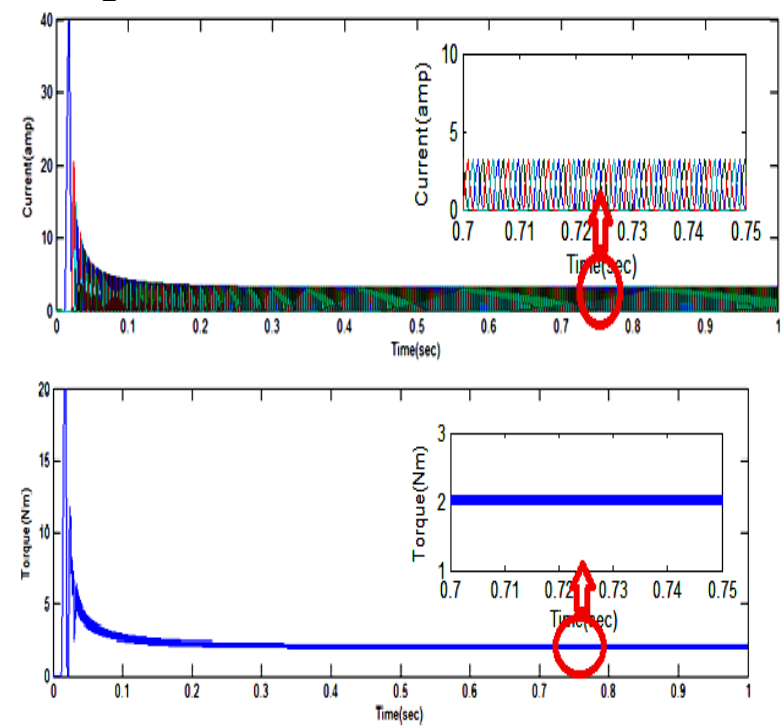

Figure 8 Current and Torque response at 50\% of the load torque with rated speed

The torque reaction bend above is augmented to show the precise variety of torque under determined burden condition as for the wide variety of speed. The variety is watched and appeared in Figure 9.
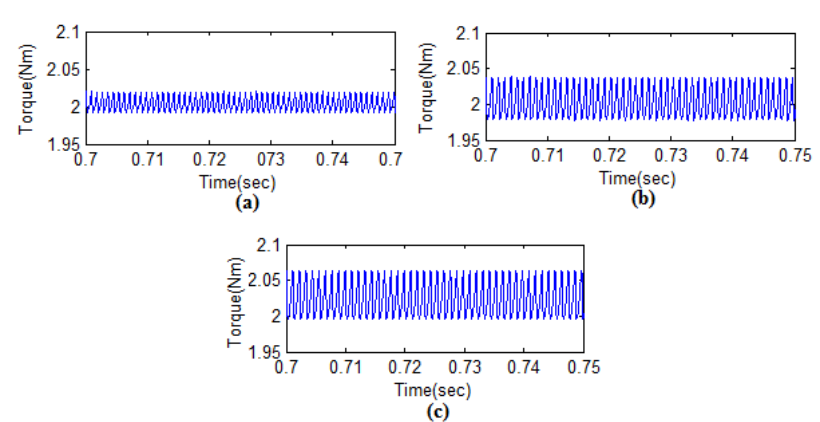

Figure 9 Torque response at $50 \%$ of the rated load

\section{(a) Rated speed (b) half rated speed (c) $10 \%$ of rated speed}

The reaction bend (an) appeared above speaks to that the torque yield (Tout) arrives at the half-appraised torque in $0.04 \mathrm{~s}$ and from that point forward, the yield torque fluctuates between a greatest torque (Tmax) of $2.02 \mathrm{Nm}$ and a base torque (Tmin) of $1.99 \mathrm{Nm}$. The normal torque yield (Tavg) has been seen as $2.00 \mathrm{Nm}$. The wave torque yield is determined in rate as $1.5 \%$. The torque swell bend (b) indicated above shows that the torque yield (Tout) arrives at the half-appraised torque in $0.04 \mathrm{~s}$ and from that point onward, the yield torque differs between a most extreme torque (Tmax) of $2.04 \mathrm{Nm}$ and a base torque (Tmin) of $1.99 \mathrm{Nm}$. The normal torque yield (Tavg) has been seen as $2.01 \mathrm{Nm}$. The torque swell yield in rate can be determined as $2.48 \%$. The bend (c) referenced above uncovers that the torque yield (Tout) arrives at the half evaluated torque in $0.04 \mathrm{~s}$ and from that point onward, the yield torque fluctuates between a most extreme torque (Tmax) of $2.06 \mathrm{Nm}$ and a base torque (Tmin) of $1.99 \mathrm{Nm}$. The torque swell in rate is determined as $3.48 \%$.

\subsection{Performance at $25 \%$ of the rated load torque}

The SRM dive is stimulated with $25 \%$ load torque and at different rated speed. The corresponding response curves are shown in Figure 10 and it is observed that maximum current of $2 \mathrm{~A}$ is reached during the rated condition. 

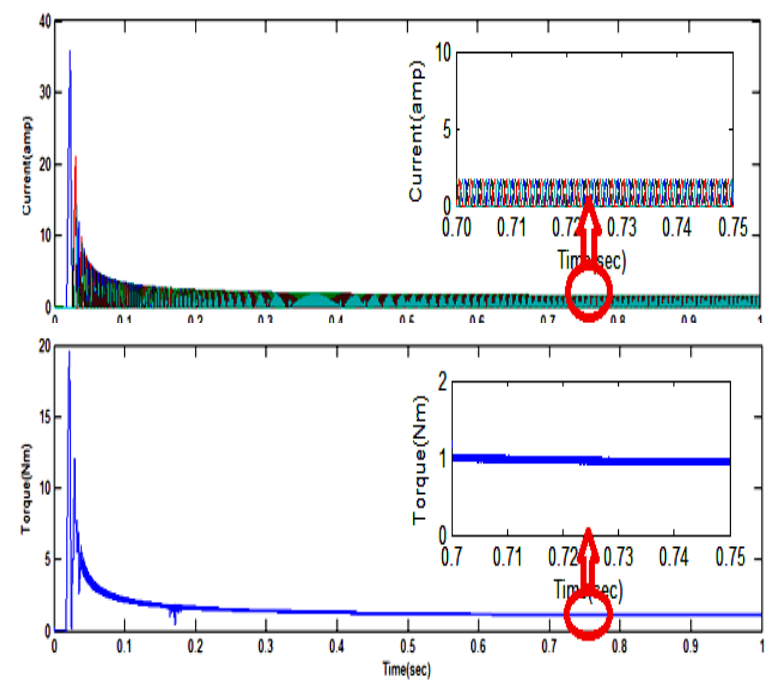

Figure 10 Current and torque profile for $25 \%$ of the load torque at rated speed

The torque reaction bend is made clearness to show the exact variety of torque under $25 \%$ of the evaluated

load condition as for the variable speed condition. The variety is watched and appeared in Figure 11. The bend (an) appears above indicated that the torque yield (Tout) arrives at the $25 \%$ appraised torque in $0.04 \mathrm{~s}$ and, from that point onward, the yield torque changes between a most extreme torque (Tmax) of $1.01 \mathrm{Nm}$ and a base torque (Tmin) of $0.999 \mathrm{Nm}$. The normal torque yield (Tavg) has been seen as $1.00 \mathrm{Nm}$. The torque swell in rate is $1.1 \%$. The torque reaction bend (b) referenced above shows that the torque yield (Tout) arrives at the 25\% evaluated torque in $0.04 \mathrm{~s}$ and from that point onward, the yield torque differs between a greatest torque (Tmax) of $1.015 \mathrm{Nm}$ and a base torque (Tmin) of $0.999 \mathrm{Nm}$. The normal torque yield (Tavg) has been seen as $1.0 \mathrm{Nm}$. The rate torque swell under the proposed condition is determined as $1.6 \%$. The reaction bend (c) portrays above shows that the torque yield (Tout) arrives at the 25\% appraised torque in $0.04 \mathrm{~s}$ and from that point onward, the yield torque fluctuates between a greatest torque (Tmax) of $1.015 \mathrm{Nm}$ and a base torque (Tmin) of $0.995 \mathrm{Nm}$. The normal torque yield (Tavg) has been seen as $1.001 \mathrm{Nm}$. The torque swell in rate is determined as $1.9 \%$.

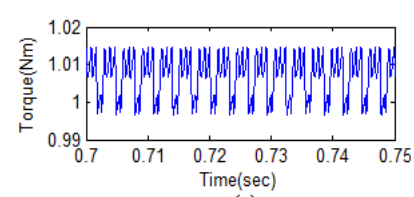

(a)

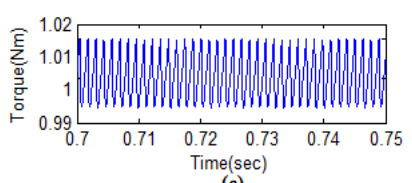

(c)

Figure 11 Torque profile for $25 \%$ of the load torque

(a) Rated speed (b) half rated speed (c) $10 \%$ of rated speed

\subsection{Performance under Variable Load condition}

In the recreation conveyed under unique condition, the speed was kept at appraised condition and it is made steady. Three cases were thought of: in the principal case, as appeared in Figure 12, the order torque, Tcom was changed from $2 \mathrm{Nm}$ to 4 $\mathrm{Nm}$ at $0.41 \mathrm{~s}$ while, in the subsequent case, Tcom was changed from $4 \mathrm{Nm}$ to $2 \mathrm{Nm}$ at $0.82 \mathrm{~s}$. From the figure, it turns out to be evident that the dynamic execution of the controller is awesome. The yield torque compasses to $2 \mathrm{Nm}$ at $0.01 \mathrm{~s}$.

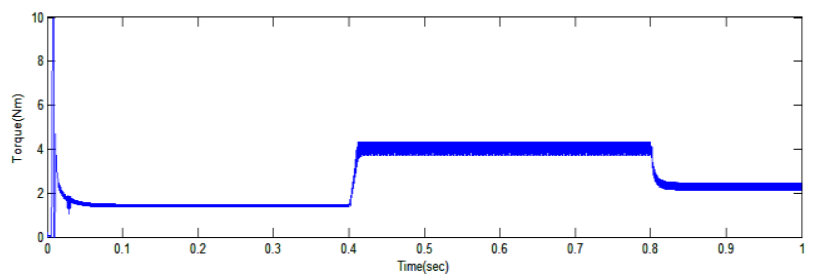

Figure 12 Torque profile under variable load condition

However, during the beginning, the torque swell is higher contrasted and those in the consistent state. At this condition, the stage current is likewise determined to be higher than the appraised current. This is because of the way that the engine requires bigger capacity to quicken during beginning, the current drawn and the torque created during beginning are enormous which will lessen the qualities comparing to the consistent state ones. The high beginning yield torque and current show that the engine ought to have brief length over-burden capacity. 
The test is conveyed with the proposed controller and the watched outcomes are contrasted and different controllers recommended in the past section are delineated in Table 1. The table beneath represents the measurable boundaries, for example, torque wave and settling time (Ts) for various controllers are referenced. From the outcomes, it is uncovered that torque swell is insignificantly decreased in the proposed controller contrasted and the other controller. The Test is directed with various burden and speed conditions. The heap torque is characterized as appraised $75 \%$ of the evaluated half of the evaluated and $25 \%$ of the evaluated. Also, the speed is fluctuated as for evaluated speed half of the appraised speed and 10\% of the evaluated speed. The torque swell is estimated at various moment in DTC technique utilizing the proposed controller.

\section{Table 1 Performance comparison between} different controller based DTC

\begin{tabular}{|c|c|c|c|c|c|c|c|}
\hline \multirow[t]{2}{*}{$\begin{array}{l}\text { S. } \\
\text { No }\end{array}$} & \multirow[t]{2}{*}{$\begin{array}{l}\text { Propo } \\
\text { sed } \\
\text { Contr } \\
\text { oller } \\
\text { based } \\
\text { DTC }\end{array}$} & \multirow[t]{2}{*}{$\begin{array}{c}\text { Rat } \\
\text { ed } \\
\text { Spe } \\
\text { ed } \\
\text { in } \\
\%\end{array}$} & \multicolumn{4}{|c|}{$\begin{array}{l}\text { Torque ripple } \\
\text { in \% with } \\
\text { respect to the } \\
\% \text { Applied load } \\
\text { torque }\end{array}$} & \multirow[t]{2}{*}{$\begin{array}{c}\text { Computa } \\
\text { tional } \\
\text { Time(sec) }\end{array}$} \\
\hline & & & $\begin{array}{c}10 \\
0\end{array}$ & $\begin{array}{l}7 \\
5\end{array}$ & 50 & $\begin{array}{l}2 \\
5\end{array}$ & \\
\hline \multirow[t]{3}{*}{1} & \multirow{3}{*}{$\begin{array}{l}\text { Hyster } \\
\text { esis } \\
\text { Contro } \\
\text { ller }\end{array}$} & 100 & $\begin{array}{c}6 . \\
0\end{array}$ & $\begin{array}{l}5 . \\
0\end{array}$ & $\begin{array}{l}4 . \\
9\end{array}$ & $\begin{array}{l}2 . \\
0\end{array}$ & \multirow[t]{3}{*}{$\begin{array}{l}\text { Equal to } \\
\text { run time }\end{array}$} \\
\hline & & 50 & $\begin{array}{c}6 . \\
48\end{array}$ & $\begin{array}{l}6 . \\
4\end{array}$ & 6 & $\begin{array}{l}2 . \\
5\end{array}$ & \\
\hline & & 10 & $\begin{array}{l}7 . \\
4\end{array}$ & $\begin{array}{l}7 . \\
2\end{array}$ & $\begin{array}{l}6 . \\
9\end{array}$ & $\begin{array}{l}3 . \\
0\end{array}$ & \\
\hline \multirow[t]{3}{*}{5} & \multirow{3}{*}{$\begin{array}{c}\text { ANFIS } \\
\text { Contro } \\
\text { ller }\end{array}$} & 100 & $\begin{array}{l}2 . \\
25\end{array}$ & 2 & $\begin{array}{l}1 . \\
5\end{array}$ & $\begin{array}{l}1 . \\
1\end{array}$ & \multirow[t]{3}{*}{7.66} \\
\hline & & 50 & $\begin{array}{l}2 . \\
97\end{array}$ & $\begin{array}{l}3 . \\
3\end{array}$ & $\begin{array}{l}2 . \\
48\end{array}$ & 1. & \\
\hline & & 10 & $\begin{array}{l}3 . \\
75\end{array}$ & $\begin{array}{l}3 . \\
6\end{array}$ & $\begin{array}{l}3 . \\
46\end{array}$ & $\begin{array}{l}1 . \\
9\end{array}$ & \\
\hline
\end{tabular}

The deliberate torque swell is contrasted and the other controller-based DTC and the traditional DTC method for the equivalent working conditions. From the examination it appears to be obvious that the torque swell got in ANFIS based DTC is nearly least which thus expands the effectiveness of the drive.

\section{Experimental Verification and Results}

The proposed controller fed direct torque control is verified in a $1.5 \mathrm{~kW}, 8 / 6 \mathrm{SRM}$ drive shown in Figure 12. FPGA SPARTAN $3 \mathrm{~A} / 3 \mathrm{~A}$ is used to implement the genetic neuro controller and the experimental results are observed with the help of digital storage oscilloscope. In the experiment setup, flux reference is set as $0.3 \mathrm{~Wb}$ and the hysteresis bandwidth is fixed as 0.02 . The drive is driven by $\pm 120 \mathrm{~V} D C$, rated speed of $3800 \mathrm{rpm}$, load torque of $4 \mathrm{Nm}$, aligned and unaligned inductance of $49 \mathrm{mH}$ and $10 \mathrm{mH}$ along with the inertia and friction is set as $0.08 \mathrm{~kg} . \mathrm{m} . \mathrm{m}$ and $0.01 \mathrm{~N}$.m.s. The SRM drive is tested under different operating conditions both static and dynamic condition. The sampling time of the digital controller is set as $2 \mu \mathrm{s}$.

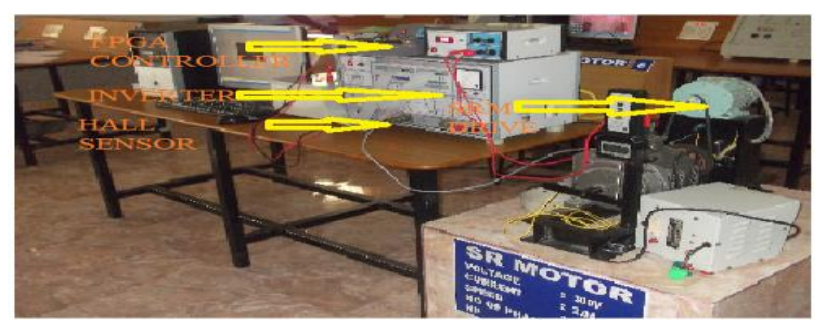

Figure 13 Experimental Setup of SRM drive

\subsection{At rated Load Condition}

The proposed controller based DTC fed switched reluctance motor is operated at various operating points in steady state conditions. Initially the motor rated torque is set at $4 \mathrm{Nm}$ and the rated speed

is fixed at $3800 \mathrm{rpm}$. Figure 14 shows the current for the four phase with the rated speed and the rated load torque. The current drawn by the SRM in experiment is $8 \mathrm{~A}$ which is equivalent to the current drawn in the simulation. 


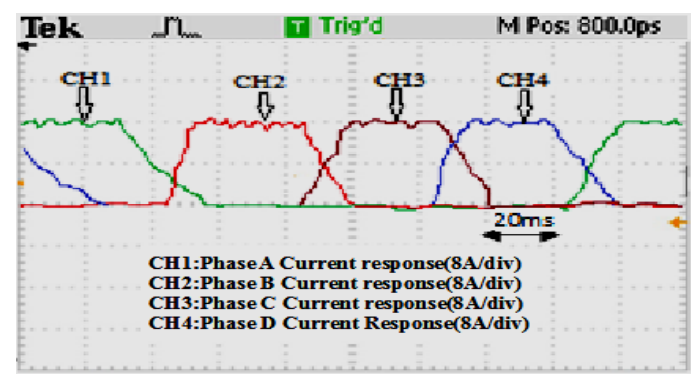

Figure 14 Current responses at rated operating condition

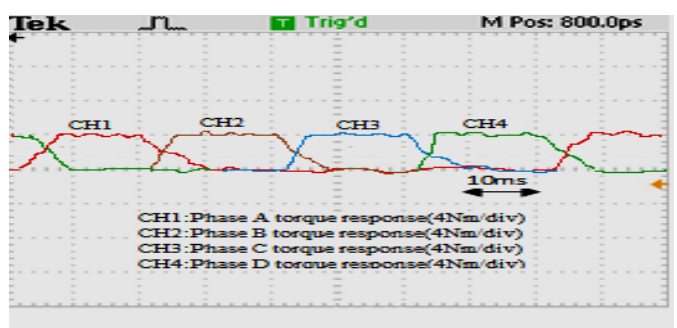

(a)

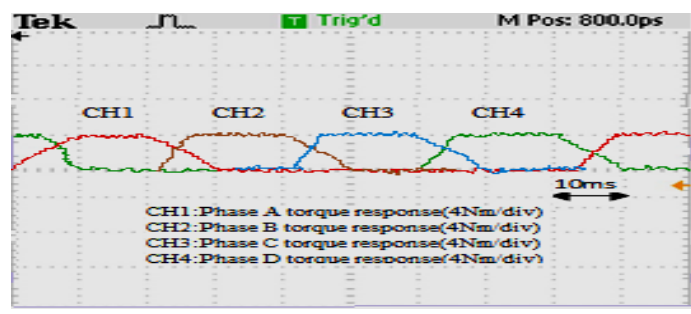

(b)

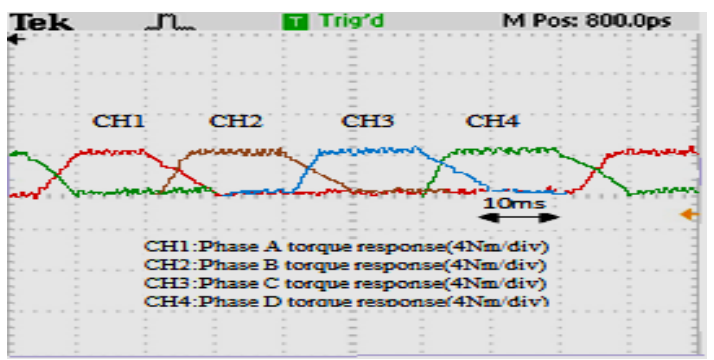

(c)

Figure 15 Torque response at rated load condition

(a) Rated Speed (b) half rated speed (c) $10 \%$ of rated speed

\subsection{At variable Load conditions}

The efficiency of the proposed controller is tested not only on the various operating speeds but also examined in various operating loads. The results are observed and tabulated to show the performance improvement of the proposed controller at various load torques. Initially the motor is loaded with $2 \mathrm{Nm}$ rated torque $(50 \%)$ of the rated torque with the same operating conditions. The results are observed and shown in the Figure 16.

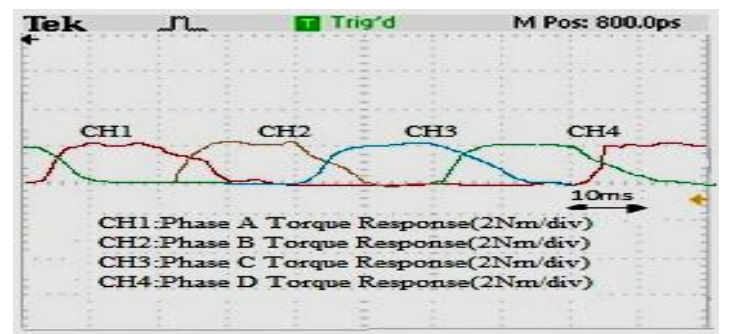

(a)

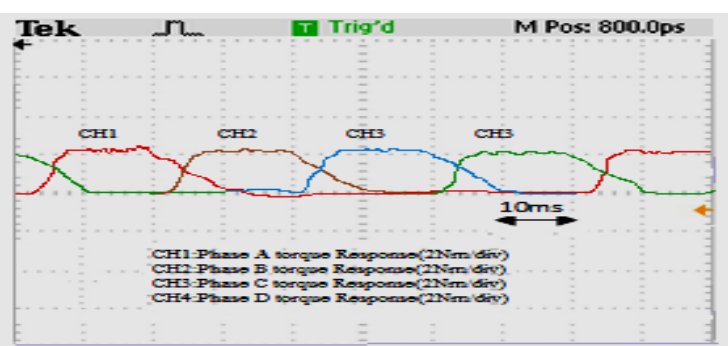

(b)

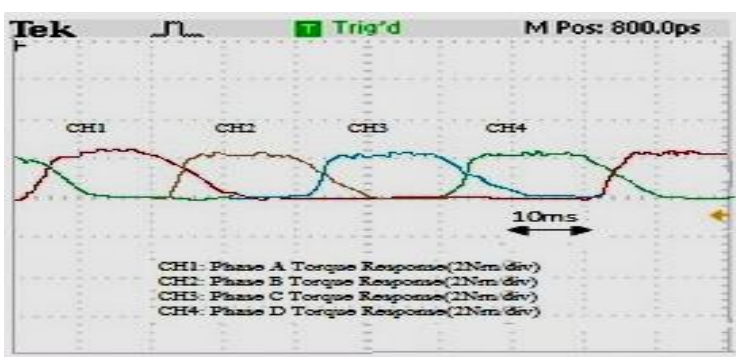

(c)

Figure 16 Torque response at half rated load

(a) Rated speed (b) half rated speed (c) $10 \%$ of rated speed

The above measured torque ripple at different operating speed varies between $1.8 \%$ to $2.7 \%$.It is quite similar to the results reveled in the simulation where the torque ripple varies in the range of $1.5 \%$ to $3.46 \%$ for the same load torque and variable speed condition which proves the characteristics of the motor in real time.

The results show that the torque ripple measured in the experiment setup varies in the range of $2.4 \%$ to $3.9 \%$ which is similar to the results 
reveled in the simulation with respect to the torque ripple which varies in the range of $2.25 \%$ to $3.75 \%$ for rated speed. The results show that the reduction in torque ripple is quite improved in the proposed controller based DTC fed drive. The Table 2 shows the compartive results between the experimental setup and the simulation output at different operating points.

Table 2 Comparative analysis between simulation output and experimental results

\begin{tabular}{|c|c|c|c|c|c|c|c|}
\hline \multirow[t]{2}{*}{$\begin{array}{c}\text { S. } \\
\text { No }\end{array}$} & \multirow[t]{2}{*}{$\begin{array}{c}\text { Propose } \\
\text { d } \\
\text { Controll } \\
\text { er based } \\
\text { DTC }\end{array}$} & \multirow[t]{2}{*}{$\begin{array}{c}\text { Rat } \\
\text { ed } \\
\text { Spe } \\
\text { ed } \\
\text { in } \\
\%\end{array}$} & \multicolumn{4}{|c|}{$\begin{array}{l}\text { Torque ripple in } \\
\% \text { with respect } \\
\text { to the \% } \\
\text { Applied load } \\
\text { torque }\end{array}$} & \multirow[t]{2}{*}{$\begin{array}{c}\text { Simula } \\
\text { tion } \\
\text { Time } \\
\text { (sec) }\end{array}$} \\
\hline & & & $\begin{array}{c}10 \\
0\end{array}$ & $\begin{array}{l}7 \\
5\end{array}$ & 50 & $\begin{array}{l}2 \\
5\end{array}$ & \\
\hline \multirow[t]{3}{*}{1} & \multirow{3}{*}{$\begin{array}{l}\text { Simulati } \\
\text { on } \\
\text { Results }\end{array}$} & 100 & $\begin{array}{c}2 . \\
25\end{array}$ & 2 & $\begin{array}{l}1 . \\
5\end{array}$ & $\begin{array}{l}1 . \\
1\end{array}$ & \multirow[t]{3}{*}{7.66} \\
\hline & & 50 & $\begin{array}{l}2 . \\
97\end{array}$ & $\begin{array}{l}3 . \\
3\end{array}$ & $\begin{array}{l}2 . \\
48\end{array}$ & 1. & \\
\hline & & 10 & $\begin{array}{l}3 . \\
75\end{array}$ & $\begin{array}{l}3 . \\
6\end{array}$ & $\begin{array}{l}3 . \\
46\end{array}$ & $\begin{array}{l}1 . \\
9\end{array}$ & \\
\hline \multirow[t]{3}{*}{2} & \multirow{3}{*}{$\begin{array}{l}\text { Experim } \\
\text { ental } \\
\text { Results }\end{array}$} & 100 & $\begin{array}{c}2 . \\
4\end{array}$ & $\begin{array}{l}2 . \\
4\end{array}$ & $\begin{array}{c}1 . \\
8\end{array}$ & $\begin{array}{l}1 . \\
4\end{array}$ & \multirow[t]{3}{*}{10.40} \\
\hline & & 50 & $\begin{array}{c}3 . \\
1\end{array}$ & $\begin{array}{l}3 . \\
7\end{array}$ & $\begin{array}{l}2 . \\
62\end{array}$ & 1. & \\
\hline & & 10 & $\begin{array}{l}3 . \\
9\end{array}$ & $\begin{array}{l}3 . \\
9\end{array}$ & $\begin{array}{l}3 . \\
63\end{array}$ & $\begin{array}{l}2 . \\
2\end{array}$ & \\
\hline
\end{tabular}

\section{Conclusion}

The torque swell minimisation utilizing ANFIS based DTC is expounded in this part where the proposed controller is utilized to limit he torque swell and to give better torque reaction. The recreation test was likewise led for various burden torques both in consistent mode just as in factor mode and the outcomes are appeared here. Reenactment results demonstrate that the proposed controller based direct torque control method can limit the wave content in the engine torque yield at various working conditions contrasted with other smart controller, and the Classical DTC procedure. Contrasted with the other controller the torque rippple is nearly limited in the scope of about $0.1 \%$ to $1.3 \%$ for a fixed speed with variable torque. The settling time of the torque and the reaction time of the speed can be diminished in the proposed procedure contrasted with the thought about controller which thus builds the productivity of the machine. The reproduction time or the calculation time is likewise contrasted with the previously mentioned controller. The reenactment time is around $7.66 \mathrm{sec}$ which is impressively less for constant control. The moderately late methodologies of torque-swell minimization endeavor smooth torque over a wide speed run. Despite the fact that the torque swell dynamically shifts with speed, these new methodologies are profoundly attractive for applications where the speed extend fluctuates generally. The presentation of the proposed procedure is similarly assessed and contrasted and different controllers alongside the current writing.

\section{References:}

[1]. Lakshmanan, Kalaivani \& Perumal, Subburaj \& Irudhayarajan, Willjuice, "Artificial Intelligence-based control for torque ripple minimization in switched reluctance motor drives", Acta Scientiarum - Technology, vol. 36, pp. 33-40, 2014.

[2]. Antoni Arias, Xavier Rain, Mickaël Hilairet, "Enhancing the flux estimation based sensorless speed control for switched reluctance machines", Electric Power Systems Research, vol. 104, pp. 62-70. 2013

[3]. A Veera Reddy, B Mahesh Kumar, "Torque Ripple minimization of Switched Reluctance Motor using Pole Embrace and Pole Configuration Methods", International Journal of Applied Engineering Research, vol. 13, no. 10, pp. 8525-8529, 2018.

[4]. Jia-Jun Wang, "A common sharing method for current and flux-linkage control of switched reluctance motor", Electrical Power System Research, vol.131, pp. 19-30, 2016.

[5]. Behzad Mirzaeian Dehkordi, Amir Parsapoor, Mehdi Moallem, Caro Lucas, "Sensorless speed control of Switched Reluctance Motor using brain emotional learning based Intelligent 
controller", Energy conversion and Management. Vol. 52, no. 1, pp. 85-96, 2011.

[6]. Viswanathan, Pushparajesh \& Thathan, Manigandan, "Minimization of Torque Ripple in Direct Torque Controlled Switched Reluctance Drive Using Neural Network". Asian Journal of Research in Social Sciences and Humanities, vol. 6, pp. 65, 2016.

[7]. C. Labiod, K. Srairi, B. Mahdad, M. E. H. Benbouzid, "A novel control technique for torque ripple minimization in switched reluctance motor through destructive interference", Electrical Engineering, vol. 100, pp. 481-490, 2018.

[8]. Cunhe Li, Guofeng Wang,Yan Li,Aide $\mathrm{Xu}$, "Robust adaptive neural network control for switched reluctance motor drives", Journal of Control, Measurement, Electronics, Computing and communication, vol. 59, no. 1, pp. 24-34. 2018.

[9]. Hassan El-Sayed Ahmed Ibrahim, Mohamed Said Sayed Ahmed and Khaled Mohamed Awad, "Speed control of switched reluctance motor using genetic algorithm and ant colony based on optimizing PID controller", International Conference on Applied Mathematics, Computational Science and Systems Engineering, ITM Web of conference, vol. 6, pp. 1-8, 2018.

[10]. Pushparajesh Viswanathan, \& Manigandan Thathan, "Hybrid Controller Based Instantaneous Torque Control of Four Phase Switched Reluctance Motor", Middle East Journal of Scientific Research, vol. 23, pp. 11, 2015.

[11]. H. Torkaman, H. Khanbabaei, M. S. Toulabi, A. Keyhani, "Two level current reference method for speed control of switched reluctance motors", European Journal of Power Electronics and Drives, vol. 30, no. 1, pp. 13-23, 2019.

[12]. H. A. Maksoud, "Torque Ripple Minimization of a Switched Reluctance Motor using a Torque Sharing Function based on the Overlap Control Technique", Engineering, Technology \& Applied Science Research, vol. 10, pp. 2, 2020.

[13]. Jia-Jun Wang, "Parameter optimization and speed control of switched reluctance based on evolutionary computation methods",Swarm and Evolutionary Computing, vol. 39, pp. 86-98, 2018.

[14]. Kalaivani L, Subburaj P , Willjuice Iruthayarajan M, "Speed Control of Switched Reluctance Motor with torque ripple reduction using Non-Dominated Sorting Genetic Algorithim(NSGA-II)", Electric Power and Energy Systems, vol. 53, pp. 69-77, 2013.

[15]. Kiruthika D and Susitra D, "Speed control of Switched Reluctance Motor, Indian Journal of Science and Technology, vol. 7, no. 8, pp. 1043-1048, 2014.

[16]. Mohammad Javad Navardi, Behnaz Babaghorban, AbbasKetabi, "Efficiency improvement and torque ripple minimization of Switched Reluctance Motor using FEM and Seeker Optimization Algorithm", Energy Conversion and Management, vol. 78, pp. 237244, 2014.

[17]. Nutan Saha, A. K. Panda, Sidhartha Panda(2018). Speed control of with torque ripple reduction of switched reluctance motor by many optimizing liaison technique", Journal of Electrical systems and Information technology, vol. 5, no. 3, pp. 829-842, 2018.

[18]. Rajib Mikail, Iqbal Husain, Yilmaz Sozer, Mohammad S. Islam, Tomy Sebastian, "Torque ripple minimization of switched reluctance machines through current profiling", IEEE Transcation on Industry Applications, vol. 49, no. 3, pp. 1258-1267, 2013.

[19]. Chouaib Labiod, Kamel Srairi, Belkacem Mahdad, Mohamed Toufik Benchouia \& Benbouzid MEH, "Speed control of $8 / 6$ switched reluctance motor with torque ripple reduction taking into account magnetic saturation effects", Energy Procedia,vol.74, pp. 112-121, 2015.

[20]. Chwan-Lu Tseng, Shun-Yuan Wang, ShaoChuan Chien \& Chaur-Yang Chang, "Development of a Self-Tuning TSK-Fuzzy Speed Control Strategy for Switched Reluctance Motor", IEEE Transactions on Power Electronics, vol. 27, no. 4, pp.2141 2142, 2012.

[21]. E. Gouda, M. Hamouda and A. R. A. Amin, "Artificial intelligence based torque ripple minimization of Switched Reluctance Motor drives," 2016 Eighteenth International Middle East Power Systems Conference (MEPCON), pp. 943-948, 2016.

[22]. Haifa Souilem, Nabil Derbel, Neuro-Fuzzy Control of Vehicle Active Suspension System International journal of Circuits, Systems and Signal processing (NAUN) pp 423-431, Volume 12, 2018

[23]. Yan Li, Chunzi Wang, Jingfeng Shao, Bin Zhang, Attack Probability Controllability Analysis Model Based on Attack Graph International journal of Circuits, Systems and 
Signal processing (NAUN) pp 387-398, Volume 12, 2018

[24]. Honghui $\mathrm{Mu}$, Xuejun Li, Jun Tang The Composite Control Method for Piston Stop Position of the GDI Engine International journal of Circuits, Systems and Signal processing (NAUN) pp 372-378, Volume 12, 2018

\section{Contribution of individual authors to} the creation of a scientific article (ghostwriting policy)

Author Contributions: Please, indicate the role and the contribution of each author:

Example

John Smith, Donald Smith carried out the simulation and the optimization.

George Smith has implemented the Algorithm 1.1 and 1.2 in $\mathrm{C}++$.

Maria Ivanova has organized and executed the experiments of Section 4.

George Nikolov was responsible for the Statistics.

Follow: www.wseas.org/multimedia/contributor-

role-instruction.pdf
Creative Commons Attribution License 4.0 (Attribution 4.0 International, CC BY 4.0)

This article is published under the terms of the Creative Commons Attribution License 4.0

https://creativecommons.org/licenses/by/4.0/deed.en_US 